Solid State Communications 104 (1997) pp. 451-454.

\title{
EFFECTS OF LIGHT AND X-RAY IRRADIATION ON CdS-DOPED GLASS
}

T. Miyoshi, H. Furukawa, K. Nitta, H. Okuni and N. Matsuo

Department of Electrical and Electronic Engineering, Yamaguchi University, Tokiwadai, Ube, Yamaguchi 755, Japan

(Received 9 June 1997; accepted 22 August 1997 by A. L. Efros)

Photodarkening in semiconductor-doped glass is considered to be due to photoinduced defects. Effects of light and X-ray irradiation on CdS-doped glass have been reported to investigate the nature of photoinduced defects in CdS-doped glass using ESR (electron spin resonance) and luminescence. The photoinduced defects are different from X-ray induced defects and may be located in glass near CdS nanocrystals.

Keywords: A. nanostructures, A. semiconductors, D. recombination and trapping, E. elecron paramagnetic resonance, E. luminescence 


\section{INTRODUCTION}

Semiconductor-doped glasses contain nanocrystals of semiconductors such as CdS or CdSSe. These glasses have large optical nonlinearity and a fast response time [1]. Roussignol et al. [2] reported that the response time decreased by light irradiation. This photoinduced irreversible process is called photodarkening. Photodarkening is considered to be due to trapped electrons in glass matrix [3,4] or photoinduced defects, which act as nonradiative recombination centers $[5,6]$. Here, we report effects of light and X-ray irradiation on CdS-doped glass to investigate the nature of the photoinduced defects in CdS-doped glass using ESR (electron spin resonance) and luminescence.

\section{EXPERIMENTAL PROCEDURE}

The sample investigated was CdS-doped commercial filter glass (Toshiba Y-44) of about $2.5 \mathrm{~mm}$ thickness. Concentration of CdS is $0.4 \mathrm{wt} \%$. This glass was exposed to pulsed light from an $\mathrm{N}_{2}$ laser (Usho YKN-900; wavelength $=337.1 \mathrm{~nm}$, pulse duration $=5 \mathrm{~ns}$, peak intensity $=5 \mathrm{MW} / \mathrm{cm}^{2}$, repetition rate $=1 \mathrm{~Hz}$ ) or X-ray from an X-ray diffractometer (Rigaku CN4057A2; Cu target, $35 \mathrm{kV}, 20 \mathrm{~mA}$ ) for $10 \mathrm{~min}$ at $300 \mathrm{~K}$. Penetration depth of laser light was estimated to be less than $0.2 \mathrm{~mm}$ from optical transmittance of the glass. The irradiated glass was annealed in air at $200^{\circ} \mathrm{C}$ or $400^{\circ} \mathrm{C}$ for $2 \mathrm{~h}$.

Transient characteristics of luminescence were measured using the following apparatus at $300 \mathrm{~K}$. The excitation source was another $\mathrm{N}_{2}$ laser (Laser Photonics LN120; wavelength $=337.1 \mathrm{~nm}$, pulse duration $=0.3 \mathrm{~ns}$, repetition rate $=7 \mathrm{~Hz}$ ). The laser beam was set at an angle of about $30^{\circ}$ to the normal and was focused on an area of about $1 \mathrm{~mm}^{2}$ by a quartz lens (focal length $f=150 \mathrm{~mm}$ ). Since the peak intensity of the laser light was low $\left(50 \mathrm{~kW} / \mathrm{cm}^{2}\right)$, photoinduced spectral changes were not observed. Luminescence was collected normal to the sample surface, focused on the end of an optical fiber by two quartz lenses $(f=50.8 \mathrm{~mm})$, and then led to a $27 \mathrm{~cm}$ monochromator (Jarrel-Ash Monospec 27). Time-resolved luminescene spectra were measured using an optical multichannel analyzer with a gate (Princeton Instruments D/SIDA-700). The minimum gate time was 5 ns. The ESR spectra were measured at $77 \mathrm{~K}$ using an X-band spectrometer (JES FE-1X). The first-derivative spectra were obtained by $100 \mathrm{kHz}$ modulation. The $g$-values of the 
signals were determined using a MgO:Mn marker.

\section{RESULTS AND DISCUSSION}

The main luminescence band is observed at about $430 \mathrm{~nm}$ in CdS-doped glass, Y-44, at $300 \mathrm{~K}$. This band is attributable to the band-to-band or shallow-trapping state-to-band transition [7]. Luminescence intensity decreases after light irradiation and partly recovers after annealing. On the other hand, noticeable change in the luminescence intensity is not observed upon X-ray irradiation. Transient characteristics of luminescence also change after light irradiation and annealing. Figure 1 shows the transient characteristics of luminescence from Y-44 at peak wavelength. These characteristics are similar to those in $\mathrm{Y}-45$ [8]. Intensities at $t=0 \mathrm{~ns}$ are normalized. The decay rate of luminescence from Y-44 after laser irradiation is faster than that before irradiation. This result indicates that defects are created by laser irradiation. These photoinduced defects act as nonradiative recombination centers and provide additional channels for the recombination of excited carriers, therefore the decay rate of the luminescence increases. The decay rate of the luminescence recovers its initial value after annealing at $400^{\circ} \mathrm{C}$. On the contrary, the decay rate of the luminescence changes only slightly upon X-ray irradiation. This result indicates that the photoinduced defects are different from X-ray induced defects.

ESR spectra were measured to investigate the nature of the defects. ESR signal was not observed in CdS-doped glass of Y-44 before irradiation. ESR signals appear after irradiation. Figure 2 shows ESR spectra of Y-44 at $77 \mathrm{~K}$. ESR signals are observed after light irradiation. These signals are similar to those in Y-45 [8]. The signal at about $g$ $=2.01$ observed after light irradiation is considered to be due to photoinduced defects. Spectral shape of this signal does not change after annealing at $200^{\circ} \mathrm{C}$, and this signal disappears after annealing at $400^{\circ} \mathrm{C}$. Simultaneously, the decay rate of the luminescence recovers its initial value after annealing at $400^{\circ} \mathrm{C}$. Therefore the photoinduced defects are considered to act as nonradiative recombination centers, which are related to photodarkening. ESR signal at about $\mathrm{g}=2.01$ observed after $\mathrm{X}$-ray irradiation is different from that after light irradiation. This result indicates that X-ray induced defects are different from light induced defects, and this supports the luminescence data. 
Spectral shape of the ESR signal at about $g=2.01$ observed after X-ray irradiation changes after annealing at $200^{\circ} \mathrm{C}$, and this signal almost disappears after annealing at $400^{\circ} \mathrm{C}$. This result indicate that the ESR signal at about $g=2.01$ is resolved into two signals: signal (a) with an isotropic g-value and signal (b) with nearly axial g-tensor. Signal (a) disappeares after annealing at $200^{\circ} \mathrm{C}$. This signal is similar to that observed in X-ray irradiated alkali silicate glass, and assigned to a hole located on a Si-O tetrahedron with two or three nonbridging oxygen atoms [9]. This signal decreases after annealing at about $200^{\circ} \mathrm{C}$ [9]. This result is consistent with our result. We also observed similar signal in X-ray irradiated glass which does not contain CdS. This signal disappeares after annealing at $200^{\circ} \mathrm{C}$. On the other hand, signal (b) was not observed in X-ray irradiated glass which does not contain CdS. Thus, signal (b) may be related to $\mathrm{Cd}$ ions in glass. Although Cd and S form CdS nanocrystals in glass by thermal treatment at about 600$700^{\circ} \mathrm{C}$, small amount of $\mathrm{Cd}$ may remain in glass matrix. We observed signal (b) in CdS-doped glass after $\mathrm{KrF}$ laser light irradiation. Since wavelength of $\mathrm{KrF}$ laser light is short $(248 \mathrm{~nm})$, light is absorbed by glass matrix. This result indicates that signal (b) is related to defects created directly in glass.

Spectral shape of the ESR signal at about $g=2.01$ observed after light irradiation does not change after annealing at $200^{\circ} \mathrm{C}$, and this signal almost disappears after annealing at $400^{\circ} \mathrm{C}$. This signal is similar to that observed in irradiated borosilicate glass: $x$ CdO- $(65-$ $x) \mathrm{ZnO}-17.5 \mathrm{~B}_{2} \mathrm{O}_{3}-17.5 \mathrm{SiO}_{2}$ [10]. This signal is assigned to a trapped hole on a nonbridging oxygen atom neighboring on an $\mathrm{Si}$ atom $(\equiv \mathrm{Si}-\mathrm{O} \cdot)$. The ESR signal associated to the nonbridging oxygen atom almost disappears after annealing at $400^{\circ} \mathrm{C}$ [11]. This result is consistent with our result. In addition to this, the nonbridging oxygen atom reacts with hydrogen [12]. This result is also consistent with our result, since we observed that the ESR signal at about $g=2.01$ decreased after hydrogenation [13].

The ESR signal at about $\mathrm{g}=1.99$ observed after light irradiation is similar to that after X-ray irradiation. This signal disappears after annealing at $200^{\circ} \mathrm{C}$. However, the decay rate of the luminescence only partly recovers after annealing. Thus, the defects related to the signal is not responsible for photodarkening. Since X-ray induced defects may be located in glass, the defects related to the signal at about $\mathrm{g}=1.99$ may be located 
in glass matrix. The signal at about $g=1.99$ is similar to that observed in irradiated borosilicate glass: $x \mathrm{CdO}-(65-x) \mathrm{ZnO}-17.5 \mathrm{~B}_{2} \mathrm{O}_{3}-17.5 \mathrm{SiO}_{2}, x=5$ and 10 [10]. This signal is assigned to a trapped electron on a $\mathrm{Cd}^{2+}$ ion in glass. The intensity ratio of the signal at about $g=1.99$ to that at about $g=2.01$ decreases upon intense X-ray irradiation. This is consistent with the fact that number of $\mathrm{Cd}$ atoms is about 1/100 of those of $\mathrm{Si}$ and $\mathrm{O}$ atoms in glass. The signal at about $g=1.99$ is not observed in glass which does not contain CdS [8]. This result supports the assignment described above.

Dependence of ESR intensity on irradiation intensity and irradiation time was also measured. The intensity of the photoinduced signal is proportional to $I^{0.5}[14]$, where $I$ is irradiation intensity. On the contrary, the intensity of the X-ray induced signal is proportional to $I$. The intensity of the photoinduced signal increases with irradiation time, and then saturates. On the other hand, saturation is not observed in the X-ray induced signal. The saturation of the photoinduced signal is explained by assuming partial annihilation of photoinduced defects during irradiation. The photoinduced defects are considered to be created with carriers ejected from semiconductor nanocrystals by twostep excitation process. Thus, rate of creation is proportional to $I^{1.5}[4]$. On the other hand, photoinduced defects partly annihilate during irradiation. Rate of photoinduced annihilation is considered to be proportional to $I$. The rate equation of defects is

$$
d N / d t=A_{1} I^{1.5}-A_{2} N I
$$

The solution of equation (1) is

$$
N=A_{1} I^{0.5}\left[1-\exp \left(-A_{2} I t\right)\right] / A_{2} .
$$

The equation (2) reproduces saturation. Furthermore, the equation also reproduces dependence of signal intensity on irradiation intensity. The value of $\mathrm{N}$ is proportional to $I^{0.5}$ in saturated region. Detailes will be published elsewhere [15].

\section{SUMMARY}

Luminescence and ESR spectra of the light or X-ray irradiated CdS-doped glass were measured to investigate the nature of photoinduced defects. The photoinduced defects are different from X-ray induced defects and may be located in glass near CdS nanocrystals. 
Acknowledgements - We are grateful to Professor T. Miki for providing permission to use his ESR spectrometer. 


\section{References}

1) Jain, R. K. and Lind, R. C., J. Opt. Soc. Am., 73, 1983, 647.

2) Roussignol, P., Ricard, D., Lukasik, J. and Flytzanis, C., J. Opt. Soc. Am., B 4, 1987, 5.

3) Grabovskis, V. Ya., Dzenis, Ya. Ya., Ekimov, A. I., Kudryavtsev, I. A., Tolstoi, M. N. and Rogulis, U. T., Sov. Phys. Solid State, 31, 1989, 149.

4) Malhotra, J., Hagan, D. J. and Potter, B. G., J. Opt. Soc. Am., B 8, 1991, 1531.

5) Van Wonterghem, B., Saltiel, S. M., Dutton, T. E. and Rentzepis, P. M., J. Appl. Phys., 66, 1989, 4935.

6) Tomita, M. and Matsuoka, M., J. Opt. Soc. Am., B 7, 1990, 1198.

7) Misawa, K., Yao, H., Hayashi, T. and Kobayashi, T., Chem. Phys. Lett., 183, 1991, 113.

8) Miyoshi, T., Towata, K. and Matsuo, N., Jpn. J. Appl. Phys., 33, 1994, 6299.

9) Schreurs, J. W. H., J. Chem. Phys., 47, 1967, 818.

10) Kawazoe, H., Suzuki, R., Inoue, S. and Yamane, M., J. Non-Cryst. Solids, 111, 1989, 16.

11) Nagasawa, K., Hoshi, Y., Ohki, Y. and Yahagi, K., Jpn. J. Appl. Phys., 25, 1986, 464.

12) Griscom, D. L., J. Non-Cryst. Solids, 68, 1984, 301.

13) Miyoshi, T., Nitta, K., Towata, K. and Matsuo, N., Jpn. J. Appl. Phys. 36, 1997, to be published.

14) Miyoshi, T., Towata, K. and Matsuo, N., Proc. Int. Conf. Optical Properties of Nanostructures, Sendai, 1994, Jpn. J. Appl. Phys., 34, 1995, Suppl. 34-1, 46.

15) Kaneda, T., Miyoshi, T., Furukawa, H., Nitta, K., Okuni, H. and Matsuo, N., Nonlinear Opt., to be published. 


\section{Figure captions}

Fig. 1. Transient characteristics of luminescence from CdS-doped glass, Y-44, at $300 \mathrm{~K}$. Intensities at $t=0 \mathrm{~ns}$ are normalized. Solid curves were drawn through data points as guide to the eyes.

Fig.2. ESR spectra of CdS-doped glass, Y-44, at $77 \mathrm{~K}$. 
Fig. 1

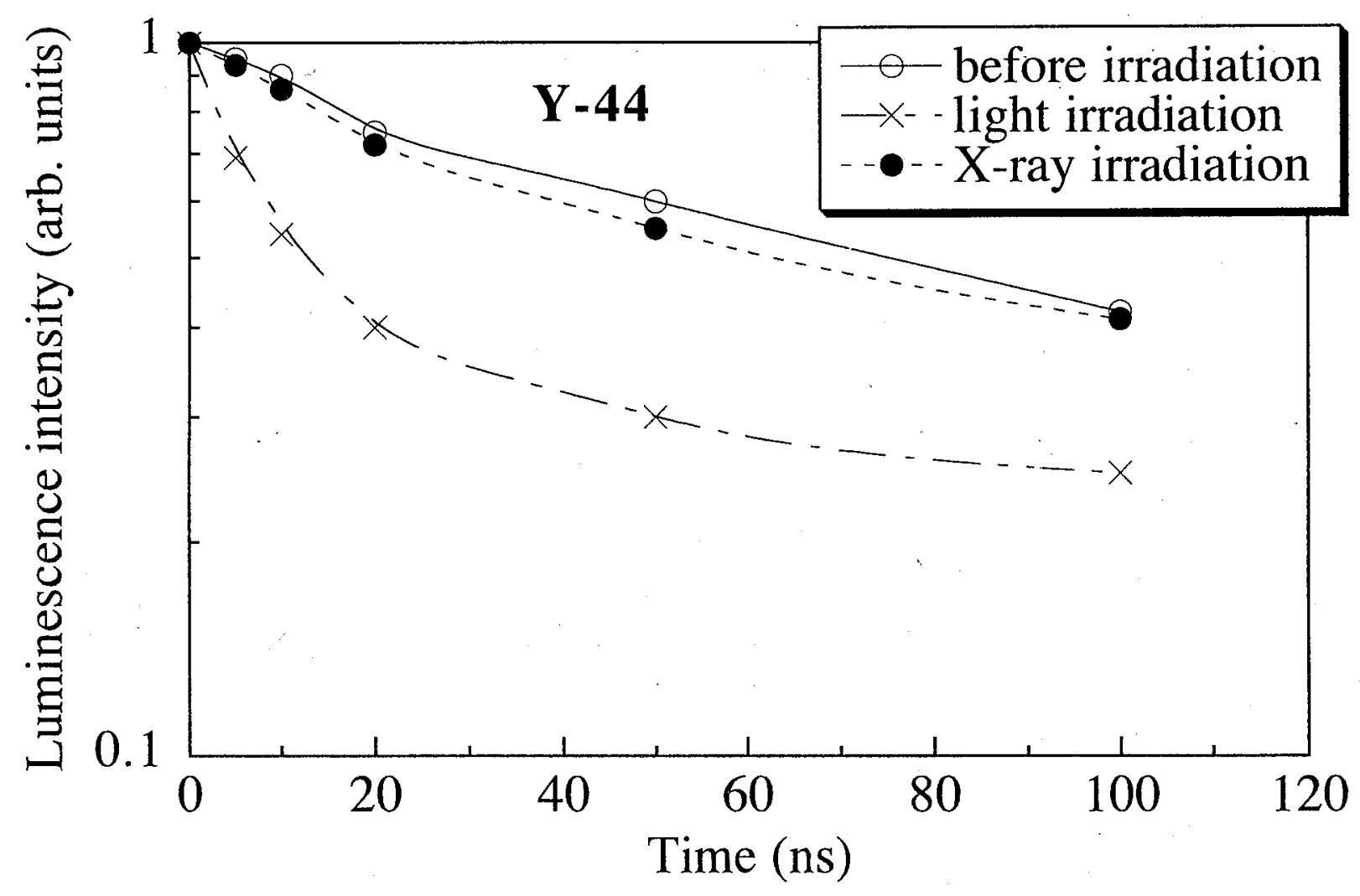


Fig. 2
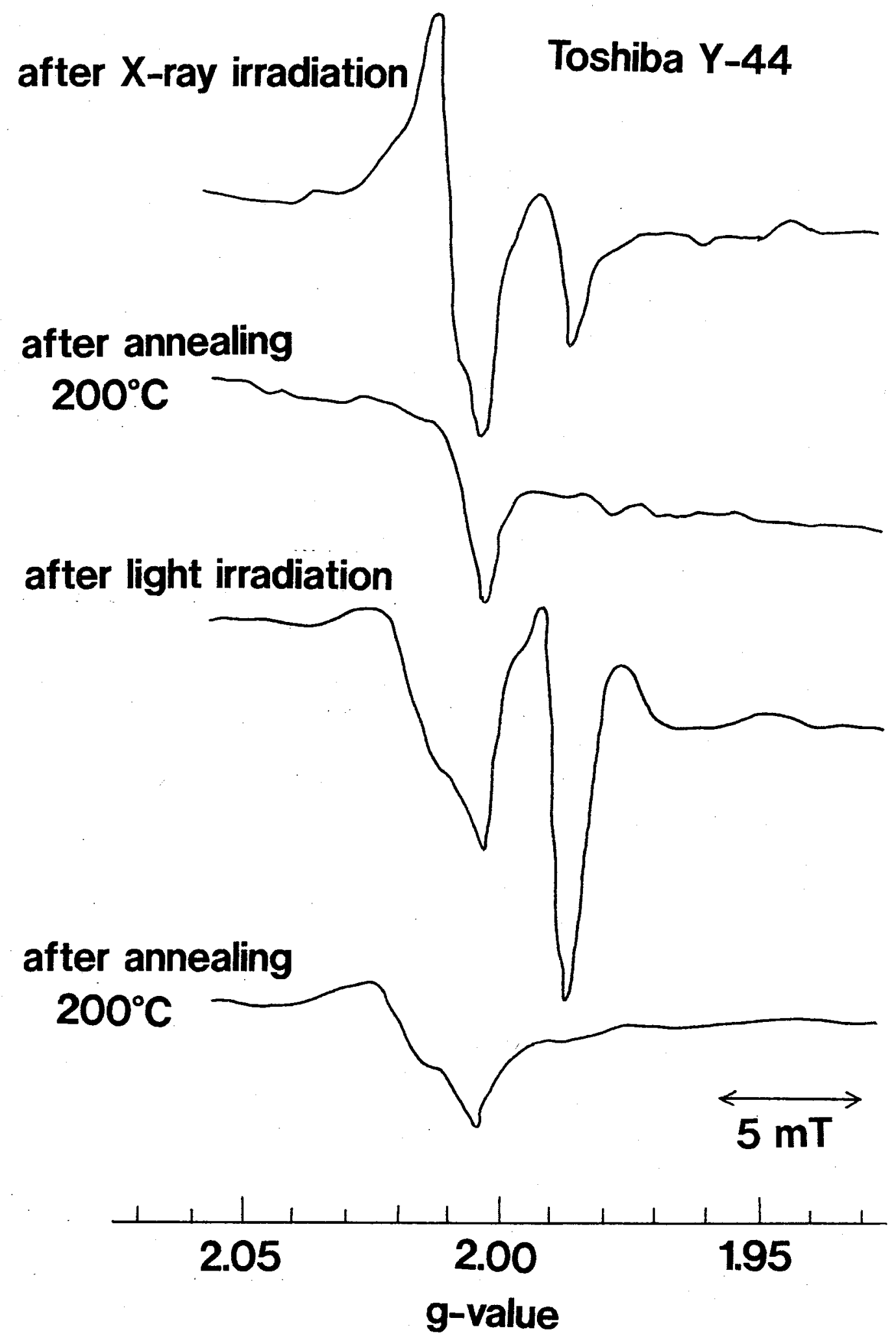